\title{
Dose Underwriter Credit and its Guiding Function Have Impact on IPO Break in China?
}

\author{
Chang $\mathrm{Xu}^{1}$ \\ ${ }^{1}$ College of Economics and Management, Nanjing University of Aeronautics and Astronautic, Nanjing, China \\ Correspondence: Chang Xu, College of Economics and Management, Nanjing University of Aeronautics and \\ Astronautic, Nanjing 211106, China. Tel: 1-570-518-6590. E-mail: 420775810@qq.com
}

Received: March 6, 2017

Accepted: March 18, 2017

Online Published: April 5, 2017

doi:10.5539/ijef.v9n5p36

URL: https://doi.org/10.5539/ijef.v9n5p36

\begin{abstract}
Underwriters' pricing behavior is partially unreasonable in China, and the overreaction of investors can easily lead to IPO break. The paper explores datum of listed companies between 2009 and 2016 in A share market and establishes Logistic Regression Model, aimed to pro how Underwriter Credit and Investor Sentiment affecting IPO break. Conclusions are as follows: overpricing of new shares will make IPO break easier; Underwriters Credit have opposite effect on IPO break; Investor Sentiment has negative relationship with IPO break significantly; underwriters can guide Investor Sentiment by credit weekly, in order to lower the probability of IPO break.
\end{abstract}

Keywords: IPO break, underwriter credit, investor sentiment, registration system

\section{Introduction}

In foreign stock markets, IPO break on the first day is a normal phenomenon, which also exists in China. From 2000 to 2008, only three listed shares broke on the first day in China. In 2009, Chinese Securities Regulatory Commission (CSRC) restarted IPO and launched the first round of IPO reform in June, after that IPO break occurred more and more frequently. The phenomenon aroused wide attention about pricing efficiency and distribution system reform of IPO in China. According to Netease Finance data analysis, Chinese listed companies issued 349 new shares and 26 ones appeared IPO break in 2010, who issued 282 new shares in 2011 and the rate of IPO break was $27.30 \%$. In the third round of IPO reform in 2012, the rate of IPO break remained high and reached $26.45 \%$. In 2013, IPO suspended and only two new shares come into the market. IPO was restarted in 2014, and the phenomenon of IPO break was gradually under control. There was no IPO break appearing in 2014 and 2015. Till December 2016, the market issued a total of 120 new shares without IPO break.

IPO Break reflects China's imperfect IPO system, with using the Inquiry System from 2009 to 2013. In the Inquiry System, IPO break happens with frequency, therefore the stock market needs reform. The Registration System is the mainstream of IPO reform In the future. After 2013, China is in transition phase from Inquiry System to Registration System, which can be an important stage to control IPO break initially.

We find that, in Chinese stock market, the underwriters' pricing behaviors are not always rational in issuing market, while investors' overreaction is also likely to lead to IPO break in trading market. How should underwriters act to control the IPO break phenomenon? Can underwriters regulate the rising Investor Sentiment or not? Can Registration System solve the status of IPO break effectively? The paper will focus on the system to solve problem and have a more in-depth discussion.

\section{Overview of the Digest Format}

\subsection{IPO Break Phenomenon}

IPO break refers to the phenomenon that new issued shares' trading price in secondary market is lower than issuing price in primary market. This paper studies IPO break on the first day. We find that in China IPO break phenomenon occurred mainly between 2010 and 2013, and the break level increased with the year grows. IPO break does not exist from 2014 to 2016.

Scholars propose that IPO break is a spontaneous phenomenon in the new shares issuing and pricing market, with foam and self-digestion. Why does IPO break appear? Scholars believe that the main reason for the break is 
overpricing in primary market. (Mao, 2011) proves that issue price of stock has a positive impact on IPO break significantly, and Inquiry System by influencing the issue price finally affects the first-day yields, resulting in a large amount of IPO break by high-priced issue. (Luo, 2012) find that IPO break does not comply with the hypothesis of efficient market, coming to the conclusion that break is due to the inefficiency of primary market and secondary market. Any other factors that will affect IPO break? Some scholars believe the break phenomenon is caused by the imperfect IPO system, which can be improved by constrained the behaviors of issuers, underwriters and regulators in the pricing mechanism. (Cao \& Shi, 2014) argue that the risk of market should be included in the IPO pricing mechanism.

The fundamental reason of IPO break is overpricing in issuing market, then how to decide the price of new shares? Does the reaction of investors in trading market and IPO pricing mechanism affect IPO break? There is no formation of system and effective response to break this situation at home and abroad at present. Therefore, this article builds the theoretical framework through the research on the Underwriters Pricing Model, the Issuer-underwriters Game Model and guiding effect of behaviors of underwriters on Investor Sentiment. For seek of IPO break and the effective way to improve this situation.

\subsection{Theoretical Framework and Hypotheses}

Based on Asymmetric Information Theory and Behavioral Finance Theory, there are two reasons for IPO break: overpricing in issuing market and over-optimistic sentiment in trading market. Theoretical framework is shown in Fig 1.

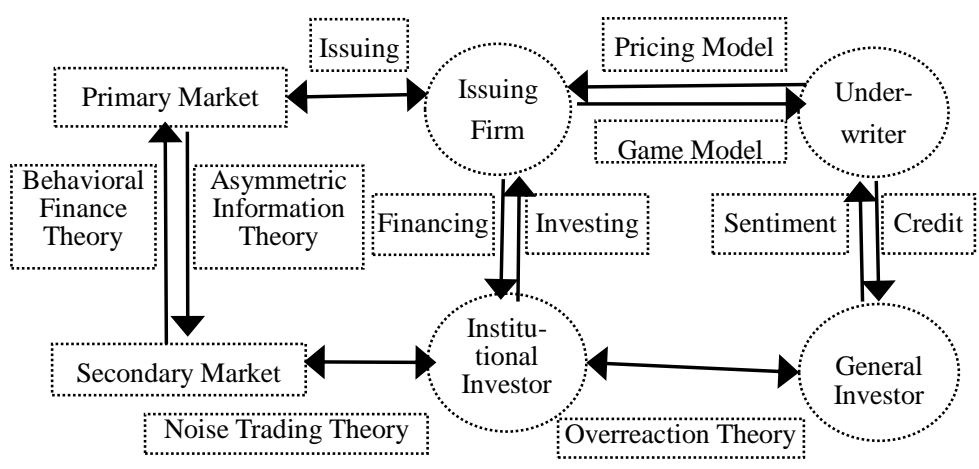

Figure 1. Theoretical framework

\subsubsection{Primary Market: Underwriters Pricing Model and Issuer-Underwriters Game Model}

First of all, we explore pricing behaviors in IPO market. Based on Asymmetric Information Theory, underwriters have more information than issuers in the process of IPO game, who are more powerful for pricing in the issue. Underwriters can take advantage of information to obtain sponsor fee and underwriting fee by conspiring with issuers and raising the price. (Zhao, 2014) uses the Game Model to analyze the behavior of various stakeholders in issuing process of IPO, and finds the relationship between overpriced shares and underwriters' reputation.

Reputable underwriters can reduce the degree of information asymmetry. Underwriter Reputation Model (1986) argues that issuers tend to select the underwriter with high reputation in IPO process. The higher the reputation underwriters have, the more valuable the recognition gotten from investors. The application of Reputation Model has limitations in China, (Zhang \& Wang, 2003) find that underwriters with high reputation can reduce the effect on IPO break but was not obvious. Reduced underwriters pricing efficiency may cause 'Reputation Discount'. Therefore hypothesis 1 and 2 are proposed.

Hypothesis 1: IPO price is proportional to underwriters' reputation. The higher the reputation underwriters have, the higher the issuing price is.

Hypothesis 2: Underwriters with high reputation tend not to raise prices and have reasonable IPO price, so that IPO break won't appear easily. The reputation is negatively related to IPO break.

\subsubsection{Secondary Market: Noise Trading Theory, Investor Overreaction and Underwriters' Guiding Effect}

The study find that it is necessary to explore psychological behaviors and motives causing information asymmetry, namely Behavioral Finance Theory. Noise Trading Hypothesis based on the theory proposed that the presence of noise makes stock prices deviate from intrinsic value for the long term, and noise traders have cognitive bias errors. (Miller, 1977) believes investors are optimistic to the future trend of the stock so as to 
overestimate the intrinsic value of new shares. (Delong, Shleifer, Summer, \& Waldmann, 1990) present the Investor Sentiment Theory at the earliest. (Ljunqvist et al., 2003) considers that irrational investors will become mania confused by the appearance of market. (Lamont, 2004) finds that positive feedback traders in the market, who chase and sell stocks irrationally, will push up the first-day trading price of the stock, leading to the high pricing phenomenon in the market.

The Overreaction Theory finds that investors are optimistic about the stock that already earns, and ultimately make irrational reactions that lead to stock market prices deviating from the rational range of intrinsic value. Therefore, optimistic market atmosphere will raise issuing price of new shares, which causes IPO break easily. But with the degree of asymmetric information reducing, the stock price will gradually return to the vicinity of the intrinsic value. Investor Sentiment adjusted or guided by underwriters can make profits theoretically. So hypothesized 3 is proposed.

Hypothesis 3: Investor Sentiment is proportional to IPO break, and high sentiment tends to overestimate the price of new issuing shares that will lead to IPO break.

The underwriter leads a regulating or guiding role, who can take advantage of reputation and information to guide Investor Sentiment, reducing the negative effect of high sentiment on IPO break. Underwriters rigorously select high-quality companies, perform their functions as the agency, play dominance in the new shares issuing and pricing market and reduce information asymmetry. That can finally make market sentiment returns to rationality, inhibit IPO break, thereby improving the market environment. Thus hypothesized 4 is proposed.

Hypothesis 4: The underwriter with high reputation can regulate or guide the Investor Sentiment. The greater the guiding role is, the less IPO break occurs.

\section{Detailed Text Formatting}

\subsection{Sample Selection and Data Sources}

This paper analyzes data by selecting 1337 new issuing shares from January 1st, 2009 to December 31st, 2016. That includes 96 shares in 2009, 344 shares in 2010, 278 shares in 2011, 149 shares in 2012, 2 shares in 2013, 125 shares in 2014, 223 shares in 2015 and 120 shares in 2016. Ultimately, 1322 samples valid excluding missing data and data with large degree of deviation. The data mainly come from RESSET database, partially are manual collected from the Netease Finance. Statistical data are processed in use of EXCEL 2007 and STATA 12.0 .

\subsection{Variable Selection}

In the paper, the dependent variable is the probability of IPO break, and independent variables are Underwriters Credit and comprehensive index of Investor Sentiment. Underwriter Credit is measured as dummy variables. All variables are shown in Table 1.

Table 1. List of variables

\begin{tabular}{cl}
\hline Symbol & \multicolumn{1}{c}{ Implication } \\
\hline Break & the probability of IPO break, dummy variable \\
IPOD & the degree of IPO break \\
IPO & issuing price of new shares \\
IS & comprehensive index of investor sentiment \\
Credit & reputation of underwriters, dummy variable \\
Fee & underwriting fees \\
Size & issuing scale of IPO \\
PE & price earning ratio of IPO \\
Share & ratio of the first-day circulation stock \\
Offline & oversubscription rate placing offline \\
Online & oversubscription rate issuing online \\
LotteryO & number-winning rate online \\
Turnover & turnover rate listed on the first day \\
ROE & return on equity \\
Age & age of listed companies \\
Board2 & board of issuing stock, dummy variable \\
Reform & IPO reform, dummy variable \\
\hline
\end{tabular}




\subsection{Quantitative Method}

\subsubsection{Quantification of Underwriter Credit}

Hayes firstly proposed the measure of Underwriter Credit. Currently, JM, CM and MW are the most representative ranking method overseas. In China, the method of CSRC ranking and market share are adopted. But these methods are too subjective, and have limitations.

This paper sets dummy variable, namely Credit index, to explore the impact of the Underwriter Credit on IPO break. When the lead underwriter of listed company belongs to the Top Ten Security Companies, the value of Credit is 1 , otherwise 0 . According to the ranking of comprehensive economic data in 2013, the Top Ten Security Companies are CITICS, Haitong Securities, GF, Merchants Securities, Guotai J\&A Securities, Guosen Securities, Huatai Securities, China Galaxy Securities, Citic China Securities, Shenyin\&Wanguo Securities.

\subsubsection{Quantification of Investor Sentiment}

Investor Sentiment is a subjective value orientation of investors formed in the trading behaviors. Previous studies at home and abroad divide the measurement of Investor Sentiment into direct indicator, indirect indicator and derived indicator. But the subjectivity of a single indicator is strong which is easily distorted.

In use of Principal Component Analysis, five indirect indicators are selected to constitute the IS comprehensive index. The reference of Proxies indicators: Closed-end Fund Discount Rate (CFDR), the IPO first-day rate of return in A-share market monthly (IPOR), Average Turnover Rate in Shanghai and Shenzhen Stock Exchange (ATR), On Balance Volume (OBV), Consumer Confidence Index in China (CCI) and New Investors in A-share market (NI). Variance contribution and principal component load of above variables are obtained by operating STATA 12.0 (Table 2). Finally predicting fitted values and residual errors of variables, calculating the total score, and getting the comprehensive index of Investor Sentiment.

Table 2. Principal component loading table

\begin{tabular}{cccccc}
\hline & Comp1 & Comp2 & Comp3 & Comp4 & Variance contribution \\
\hline CFDR & 0.3739 & -0.1232 & -0.0936 & -0.2925 & 0.4729 \\
ATR & 0.3945 & 0.0264 & 0.4253 & -0.1437 & 0.217 \\
OBV & 0.3499 & -0.1185 & 0.4798 & -0.1597 & 0.1216 \\
IPOR & 0.1727 & -0.0782 & 0.3026 & 0.8724 & 0.0891 \\
CCI & 0.2799 & 0.0912 & -0.399 & 0.3162 & 0.0555 \\
NI & 0.3866 & 0.2097 & 0.1777 & -0.0808 & 0.0273 \\
Characteristic root & 4.7293 & 2.1703 & 1.2159 & 0.8905 & \\
\hline
\end{tabular}

\subsection{Logistic Regression Model}

The dependent variable adopts dummy variable Break to research IPO break or not. IPO Break is a categorical variable, therefore considering nonlinear logistic regression model, short for Logistic Regression Model, to deal with the specific situation and do the empirical analysis.

\section{Figures}

\subsection{Descriptive Statistics of the Sample}

Based on the study above, it is found that IPO break phenomenon mainly occurred between 2010 and 2013. Thus, this paper analyzes 754 new shares by removing the missing data.

Table 3 shows that the probability of IPO break has the trend of increase and fluctuation substantially between 2010 and 2013. The degree of IPO break mean is negative, indicating that most new shares in the market are issued underpricing. Besides, the Underwriter Credit slightly increases year by year. The market sentiment is generally low, but has rebounded in recent years.

Table 3. Descriptive statistics by year

\begin{tabular}{cccccc}
\hline & \multicolumn{2}{c}{ Break } & \multicolumn{2}{c}{ IPOD } \\
\hline & $\mathrm{N}$ & Mean & S.D & Mean & S.D \\
\hline 2010 & 335 & 0.0746 & 0.2632 & -0.4163 & 0.4192 \\
2011 & 273 & 0.2747 & 0.4472 & -0.2093 & 0.3061 \\
2012 & 146 & 0.2671 & 0.444 & -0.2119 & 0.2908 \\
2013 & 2 & 0.5 & 0.7071 & -0.2769 & 0.4652 \\
\hline
\end{tabular}




\begin{tabular}{cccccc}
\hline & \multicolumn{2}{c}{ IS } & \multicolumn{2}{c}{ Credit } \\
\hline & $\mathrm{N}$ & Mean & S.D & Mean & S.D \\
\hline 2010 & 335 & 1.1129 & 0.6519 & 0.3493 & 0.4774 \\
2011 & 273 & 0.127 & 0.6697 & 0.3553 & 0.4795 \\
2012 & 146 & -1.0493 & 0.5597 & 0.4315 & 0.497 \\
2013 & 2 & -0.9613 & 0.1133 & & \\
\hline
\end{tabular}

In Table 4, there are 139 shares in IPO break accounting for $18.44 \%$ of total issued shares. When IPO break appears, variable Size increases significantly while LotteryO rises slightly; variables Online and Offline drop significantly, while Age and ROE decline slightly. In addition, listed shares in different Board have increased, and the impact of the Reform on IPO break is larger than that not appears.

Table 4. Descriptive statistics by IPO break or not

\begin{tabular}{ccccccc}
\hline & \multicolumn{3}{c}{ Break=0 } & \multicolumn{3}{c}{ Break=1 } \\
\cline { 2 - 7 } & $\mathrm{N}$ & Mean & S.D & $\mathrm{N}$ & Mean & S.D \\
\hline Size & 615 & 85699.22 & 87957.46 & 139 & 130846.61 & 149941.73 \\
PE & 615 & 50.9289 & 21.4995 & 139 & 45.123 & 17.4937 \\
Offline & 615 & 43.4538 & 39.0743 & 139 & 18.4115 & 22.6591 \\
Online & 615 & 151.0006 & 85.8726 & 139 & 70.6518 & 50.382 \\
LotteryO & 615 & 1.1216 & 1.457 & 139 & 3.3337 & 6.5622 \\
Turnover & 615 & 77.3226 & 11.4333 & 139 & 31.8306 & 9.9474 \\
Age & 615 & 4.3301 & 0.755 & 139 & 3.8993 & 0.6735 \\
Board2 & 615 & 0.531 & 0.4995 & 139 & 0.5526 & 0.4994 \\
Reform & 615 & 0.0992 & 0.2992 & 139 & 0.1799 & 0.3855 \\
\hline
\end{tabular}

In this paper, Spearman correlation coefficient and scatter diagram are used for further analysis of the relationship between variables. In order to fulfill the normal distribution and ensure the authenticity of data, change variables Size and Offline to the log form, and change variable LotteryO to the $1 / \mathrm{sqrt}$ form.

Utilizing $\mathrm{T}$ test for significance level detection on the whole. When $a=0.05$, T-value is 1.96 . It is found that absolute values of variables IPO, ROE, Credit and Board2 are all less than 1.96 in use of IPO break as the dependent variable. So considering removing the variables above when establishing the relevant model.

\section{Empirical Analysis}

\subsection{Model Established and Regression Analysis}

\subsubsection{Linear Regression Analysis between IPO Pricing and Underwriter Credit}

To verify Hypothesis 1 that the higher Underwriter Credit, the higher IPO price, the paper establishes a simple Linear Regression Model. Using IPO price as a dependent variable and Underwriter Credit as a independent variable. The regression results are in Table 5.

Table 5. Results between IPO pricing and underwriter credit

\begin{tabular}{ccccc}
\hline IPO & Regression 1 & S.D & T & P \\
\hline Credit & 0.5439 & 1.1319 & 0.48 & 0.63 \\
\hline
\end{tabular}

It is not significant for regression results according to the P-value. But the positive relationship between Underwriter Credit and IPO price is in line with Hypothesis 1.

\subsubsection{Analysis between Underwriter Credit and IPO Break Based on Logistic Regression Model}

In order to verify the relationship of Underwriter Credit and IPO break in Hypothesis 2, the paper establishes a Logistic Regression Model. Considering the probability of IPO break as a dependent variable and Underwriter Credit as a independent variable.

Build a simple linear regression equation:

$$
\text { Break }=\beta_{0}+\beta_{1} \text { Credit }+\varepsilon
$$

Multiple linear regression equation: 


$$
\text { Break }=\beta_{0}+\beta_{1} \text { Credit }+\beta_{2} \sum \text { Control }+\varepsilon
$$

In the case of multiple linear regression model, setting $\mathrm{P}$ as the probability of equation, where $\mu$ is the residual term, there

$$
P\left(\text { Break }=1 \mid \text { Credit }, \sum \text { Control }\right)=\Lambda\left(\text { Break }=\beta_{0}+\beta_{1} \text { Credit }+\beta_{2} \sum \text { Control }\right)+\mu
$$

The regression results are shown in Table 6.

\begin{tabular}{|c|c|c|c|c|}
\hline Break & Regression 2 & OR & Regression 3 & OR \\
\hline Credit & $\begin{array}{c}-0.0789 \\
(-0.40)\end{array}$ & 0.9241 & $\begin{array}{c}-1.6505^{* *} \\
(-2.36)\end{array}$ & 0.192 \\
\hline Online & & & $\begin{array}{c}-0.0102 * * \\
(-2.11)\end{array}$ & 0.9899 \\
\hline Turnover & & & $\begin{array}{c}-0.2654 * * * \\
(-6.88)\end{array}$ & 0.7669 \\
\hline ROE & & & $\begin{array}{c}-0.0551 * * \\
(-2.01)\end{array}$ & 0.9464 \\
\hline \multirow[t]{3}{*}{ Constant } & $\begin{array}{c}-1.4586^{* * * *} \\
(-12.46)\end{array}$ & 0.2326 & $\begin{array}{c}3.9728 \\
(0.17)\end{array}$ & 53.1312 \\
\hline & Observations & 754 & Observations & 679 \\
\hline & R-squared & 0.6868 & R-squared & 0.8606 \\
\hline
\end{tabular}

Table 6. Results between underwriter credit and IPO break

Note. Whereby $\mathrm{Z}$-values are in parentheses, $* * *$ indicates $\mathrm{p}<0.01$, ** indicates $\mathrm{p}<0.05$, * indicates $\mathrm{p}<0.1$.

In regression 2, variable Credit has insignificant impact on IPO break. After adding the control variables, the $\mathrm{R}$-value is improved greatly in regression overall and the fitting effect of equation is better. Then the negative relationship of the variable Credit and IPO break is significant in line with Hypothesis 2. With Odds Ratio (OR) of Underwriter Credit decreasing, the risk of IPO break from Credit is under control. Other significant variables such as Online, Turnover and ROE have negative correlation with IPO break, which becoming risk factors for IPO break and in need of control.

\subsubsection{Analysis between Investor Sentiment and IPO Break Based on Logistic Regression Model}

To verify the relationship of Investor Sentiment and IPO break in Hypothesis 3, the paper establishes a Logistic Regression Model. With IPO break as the dependent variable, Investor Sentiment as the independent variable, the principle is the same as above. The regression results can be seen in Table 7.

Table 7. Results between investor sentiment and IPO break

\begin{tabular}{llllll}
\hline Break & $\mathrm{N}$ & Regression 4 & OR & $\mathrm{R}$ & $\mathrm{T}$ \\
\hline $\mathrm{IS}$ & 754 & $-0.6730^{* * *}$ & 0.5102 & 0.0694 & -6.75 \\
\hline
\end{tabular}

Note. Whereby Z-values are in parentheses, *** indicates $\mathrm{p}<0.01$, ** indicates $\mathrm{p}<0.05, *$ indicates $\mathrm{p}<0.1$.

In Regression 4, R-value is 0.0694 and level of significance is not high in overall equation. Investor Sentiment and IPO break rate have significantly reverse effect, which is contrary to Hypothesis 3 . That could be caused by the particularity of immature market in China. Odds ratio is less than 1, indicating that variable IS can be a protective factor of IPO break with a lower risk.

5.1.4 Analysis between Guiding Effect of Underwriter Credit and IPO Break based on Logistic Regression Model

In order to verify the relationship between guiding effect of Underwriter Credit on Investor Sentiment and IPO break in Hypothesis 4, the paper establishes a Logistic Regression Model. Setting IPO break as a dependent variable, guiding effect of Underwriter Credit on Investor Sentiment (IS*Credit) as a independent variable.

Firstly not considering the guiding effect of Underwriter Credit, and building a multiple linear regression equation.

$$
\text { Break }=\beta_{0}+\beta_{1} I S+\beta_{2} \text { Credit }+\beta_{3} \sum \text { Control }+\varepsilon
$$

Then considering the presence of the guiding effect, and building another multiple linear regression equation, namely:

$$
\text { Break }=\beta_{0}+\beta_{1} I S+\beta_{2} \text { Credit }+\beta_{3} I S * \text { Credit }+\beta_{4} \sum \text { Control }+\varepsilon
$$


In this case, setting $\mathrm{P}$ as the probability of equation, where $\mu$ is the residual term, there

$$
\begin{gathered}
P\left(\text { Break }=1 \text { Credit, IS } * \text { Credit, } \sum \text { Control }\right) \\
=\Lambda\left(\text { Break }=\beta_{0}+\beta_{1} I S+\beta_{2} \text { Credit }+\beta_{3} \text { IS } * \text { Credit }+\beta_{4} \sum \text { Control }\right)+\mu
\end{gathered}
$$

The regression results are in Table 8 .

\begin{tabular}{|c|c|c|c|c|c|}
\hline Break & Coefficient & Regression 5 & OR & Regression 6 & OR \\
\hline IS & -0.2432 & $\begin{array}{c}-1.3846 * * \\
(-2.16)\end{array}$ & 0.2504 & $\begin{array}{c}-1.2383^{*} \\
(-1.88)\end{array}$ & 0.2899 \\
\hline Credit & -0.023 & $\begin{array}{c}-1.8082 * * \\
(-2.32)\end{array}$ & 0.1639 & $\begin{array}{c}-2.0135^{* *} \\
(-2.40)\end{array}$ & 0.1335 \\
\hline IS*Credit & -0.117 & & & $\begin{array}{c}-0.7154 \\
(-0.85)\end{array}$ & 0.489 \\
\hline Constant & & $\begin{array}{l}2.3559 \\
(0.08)\end{array}$ & 10.5473 & $\begin{array}{l}1.3217 \\
(0.04)\end{array}$ & 3.7496 \\
\hline & & $\begin{array}{c}\text { Observations } \\
\text { R-squared }\end{array}$ & $\begin{array}{c}679 \\
0.8735\end{array}$ & $\begin{array}{c}\text { Observations } \\
\text { R-squared }\end{array}$ & $\begin{array}{c}679 \\
0.8747\end{array}$ \\
\hline
\end{tabular}

Table 8. Results between guiding effect and IPO break

Note. Whereby $\mathrm{Z}$-values are in parentheses, $* * *$ indicates $\mathrm{p}<0.01$, ** indicates $\mathrm{p}<0.05$, * indicates $\mathrm{p}<0.1$.

Without considering the guiding role of Underwriter Credit for Investor Sentiment, the R-value is 0.8735 and the overall equation is significant in Regression 5. In Regression 6, the R-value is slightly improved and the explanatory power of Underwriter Credit is enhanced in consideration of the guiding effect of Underwriter Credit. The coefficient of guiding role is negative and the effect is not significant, indicating that the guiding effect is weak on reducing the probability of IPO break, which is partially in line with Hypothesis 4. Under the guidance role, Underwriter Credit improves by itself.

\subsection{Robustness Test}

In order to ensure the robustness of empirical results, the paper substitutes the IPO numbers in A-share market monthly (AIPO) for the IPO first-day rate of return in A-share market monthly (IPOR), and gets a new comprehensive index of Investor Sentiment. Then do empirical analysis in the Logistic Regression Model. The regression results indicate that Investor Sentiment still has a significant negative effect on IPO break. It is showed that empirical results of this paper pass the Robustness Test.

\section{Conclusion}

The paper selects new issued shares in A-share market from 2009 to 2016 in research of IPO break phenomenon, for exploring how do Underwriter Credit and guiding effect on Investor Sentiment influence IPO break. Drawing conclusions as follows: (1) IPO break is mainly due to overpriced in issuing market and related to behaviors of investors in trading market. (2) Underwriters Credit has significantly reverse effect on IPO break. Enhancing the credit in use of sufficient information resources can reduce the probability of IPO break. (3) Investor Sentiment has a insignificantly negative correlation with IPO break. Underwriter Credit can guide Investor Sentiment weakly for reducing the appearance of IPO break.

Strategies and suggestions are as follows in the perspective of various stakeholders and regulators. Firstly, underwriters improve their reputation and standard their behaviors in the game with listed companies. Secondly, investors remain moderately optimistic sentiment and have rational treatment with IPO break phenomenon. Thirdly, the CSRC strengthens the power of supervision and punishment and guides to improve the IPO system. Fourthly, the Registration System and Market-oriented Reforms are promoted vigorously.

\section{Acknowledgments}

This work was supported in part by my professor and roommate. Because of your inspiration and accompany, I can go further on this road and be helpful in the future career. Thank you for your help and concern.

\section{References}

Andrei, S., \& Vishny, R. W. (1997). A Survey of Corporate Governance. Journal of Finance, 52(2), 737-783. https://doi.org/10.1111/j.1540-6261.1997.tb04820.x

Benveniste, L. M., \& Spindt, P. A. (1989). How investment bankers determine the offer price and allocation of new issues. Journal of Financial Economics, 24(2), 343-361. 
https://doi.org/10.1016/0304-405X(89)90051-2

Booth, J. R., \& Richard, I. I. (1986). Capital raising, underwriting and the certification hypothesis. Journal of Financial Economics, 15(15), 261-281. https://doi.org/10.1016/0304-405X(86)90057-7

Carter, R. B., Dark, F. D., \& Singh, A. K. (1998). Underwriter reputation, initial returns, and the long-run performance of IPO stocks. Journal of Finance, 53(1), 285-311. https://doi.org/10.1111/0022-1082.104624

Ding, D. (2011). The analysis on new shares offer price breaking phenomenon. Financial Perspectives Journal, 9, 33-36.

Dorn, D. (2003). Does sentiment drive the retail demand for IPOs?. Drexel University, America. https://doi.org/10.2139/ssrn.472660

Dufwenberg, M., Lindqvist, T., \& Moore, E. (2005). Bubbles and experience. American Economic Review, 95, 1731-1737. https://doi.org/10.1257/000282805775014362

Han, L. Y., \& Wu, Y. R. (2007). Investor sentiment and IPO puzzle: Underpricing or overpricing. Management World, 3, 51-61.

Lowry, M., \& Shu, S. (2002). Litigation risk and IPO underpricing. Journal of Financial Economics, 65(3), 309-355. https://doi.org/10.1016/S0304-405X(02)00144-7

Luo, X. L. (2012). The pricing efficiency of IPO and the source of new shares falling on debut during seventh $I P O$ restart (Master's thesis, Southwestern University of Finance and Economics, Sichuan, China).

Ma, SH. J., \& Lin, J. Q. (2013). The quantification of investor sentiment and application on IPO underpricing. Statistics and Decision, 396(24), 77-80.

Megginson, W. L., \& Weiss, K. A. (1991). Venture capitalist certification in initial public offerings. Journal of Finance, 46(3), 879-903. https://doi.org/10.1111/j.1540-6261.1991.tb03770.x

Miller, E. M. (1977). Risk, uncertainty and divergence of opinion. Journal of Finance, 32(4), 1151-1168. https://doi.org/10.1111/j.1540-6261.1977.tb03317.x

Miller, E. M. (2000). Equilibrium with divergence of opinion. Review of Financial Economics, 55(1), $27-41$. https://doi.org/10.1016/S1058-3300(00)00010-0

Rock, \& Kevin. (1986). Why new issues are underpriced?. Journal of Financial Economics, 16(1), 187-212. https://doi.org/10.1016/0304-405X(86)90054-1

Song, SH. B. (2011). Research on underwriters' behavior in Chinese IPO market (Master's thesis, Dongbei University of Finance and Economics, Shandong, China).

Wang, Y. X., \& Xia, X. P. (2007). Noise trader and IPO overpricing. Journal of Management Sciences, 3, 91-97.

Welch, I. (1992). Sequential sales, learning and cascades. Journal of Finance, 47(2), 695-732. https://doi.org/10.1111/j.1540-6261.1992.tb04406.x

Willenborg, M. (1999). Empirical analysis of the economic demand for auditing in the initial public offerings market. Journal of Accounting Research, 37(1), 225-237. https://doi.org/10.2307/2491405

$\mathrm{Wu}, \mathrm{Q}$. W. (2013). The study on IPO offer price breaking on the first day and stock market performance in China (Master's thesis, University of Fudan, Shanghai, China).

Yu, L. N., \& Hu, B. (2013). The influence of new shares breaking on IPO pricing: Based on the transformation of information fees. Commercial Times, 4, 59-62.

Zou, X. F., \& Fu, Q. (2013). China underwriter's reputation in the SEO: Based on the traded-based manipulation. Chinese Journal of Management Science, 21(6), 177-184.

\section{Copyrights}

Copyright for this article is retained by the author(s), with first publication rights granted to the journal.

This is an open-access article distributed under the terms and conditions of the Creative Commons Attribution license (http://creativecommons.org/licenses/by/4.0/). 